\begin{tabular}{|c|cc|c|}
\hline & PORT SAID ENGINEERING RESEARCH JOURNAL \\
Faculty of Engineering - Port Said University \\
No. 1 \\
(Architectural Engineering)
\end{tabular}

\title{
The Chameleon Biomimetic Concept in Architectural Design: A Review
}

\author{
Yasmin M. Eid ${ }^{1}$, Mostafa A. El Ahwal ${ }^{2}$, Magda E. Ebied ${ }^{3}$, Rania H. Aly ${ }^{4}$
}

Received: 22 November 2020; Accepted: 18 January 2021

\begin{abstract}
Architects spend a lot of time and efforts trying to solve their design problems. Actually, they just need to look at and learn from the surrounding environment. Nature can achieve not only humans' requirements but also helps to solve the problems, which they make. It could be considered as a life dictionary due to the diversity that exists. That is what the biomimicry science in general aims. One of the practical fields that applies biomimicry science is architecture. Biomimetic architecture aims to redesign multiple sustainable solutions for human's subversion in the built environment. Chameleon is an amazing word that exists in this dictionary. Some of Chameleon species that live in hot arid zones can reduce about $45 \%$ of the solar heat gain only by using its skin due to the special physical components called "chromatophores". In this paper, the biomimetic architecture has been introduced. Besides, some famous case studies of architectural buildings that imitate chameleon have been reviewed, analyzed, and classified according to the biomimetic architecture levels.
\end{abstract}

Keywords: Biomimicry, Biomimicry Science, Biomimetic Architecture, Sustainability, Chameleon

\section{INTRODUCTION}

Humans over the decades have been innately connected to Nature to meet basic survival needs such as food, water, dress, and shelters. Nowadays, humans need to be in contact with nature and its complex geometrical forms. That is not less important than fulfilling their requirements of food and air needed for metabolism. [1] The whole nature including inanimate and animate creatures moves in a sustainable ecosystem cycle through 3.8 billion years without harming the environment. Many researchers defined nine legislations of nature's laws that activate this sustainable cycle. Those legislations are as shown in Figure 1. [2] [3]

Over decades, scientists developed a modern philosophy called biomimicry to translate the innate connection between humans and their natural motherland. Jenine Benyus who is considered the founder of the bio mimic philosophy defined it as "the science that examines model, systems, the process of

${ }^{1}$ Assistant Lecturer, Architecture and Urban Planning Department, Faculty of Engineering, Sinai University, North Sinai, Egypt, email: yasmen.mohamed@su.edu.eg, Corresponding Author

${ }^{2}$ Professor in Architecture and Urban planning Department, Port Saied University, Egypt, email: whitehouse.egypt@yahoo.com

3 Professor in Architecture and Urban Planning Department, Environmental Studies Institute, Ain Shams University, Cairo, Egypt, email:magda_ebeid@yahoo.com

${ }^{4}$ Lecturer in Architecture and Urban Planning Department, Port Saied University, Egypt, email: dr.ranyaaly@gmail.com

DOI: $10.21608 /$ pserj.2021.49883.1071 nature, and understand the concept that forms those principles, to reproduce multi sustainable solutions that solve the human-made problems". [2]

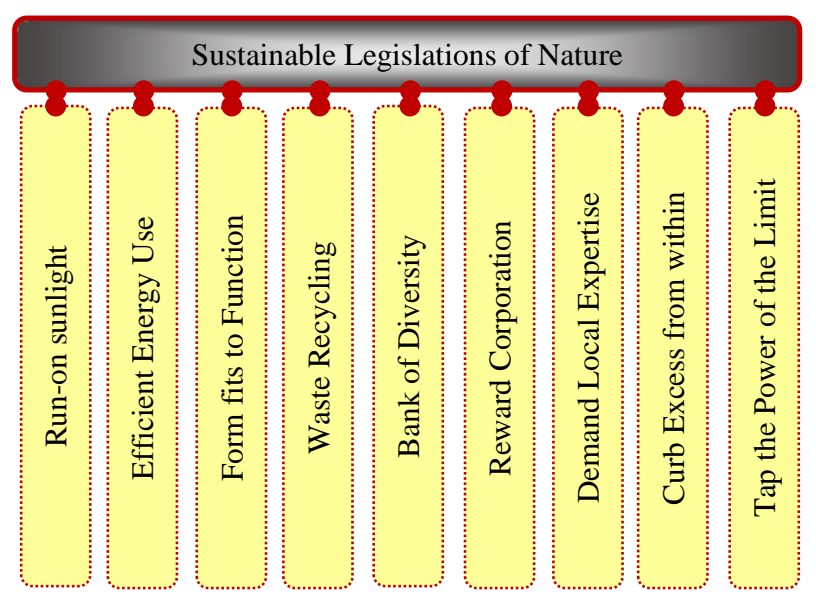

Figure 1: Nature Legislations and Laws [2]

\section{BIOMIMETIC ARCHITECTURE}

Many scientific fields including architecture applied and practiced biomimicry science. Biomimetic architecture is the sustainable design approach that imitates natural models, systems, and the process then applies them in the built environment. [4] [5] [6]

Other architectural terms such as biophilic and biomorphic may be similar to biomimetic, but they are different. Biophilic is a trend that mimics the internal and the external organisms' forms and their relations with the natural spaces. Thus, it creates a healthy built environment that aims to enhance human's wellbeing, as 
shown in Figure 2. [7][8] Biomorphic is a stylistic symbol trend that mimics the unconventional natural forms, as shown in Figure 3. [9][10]

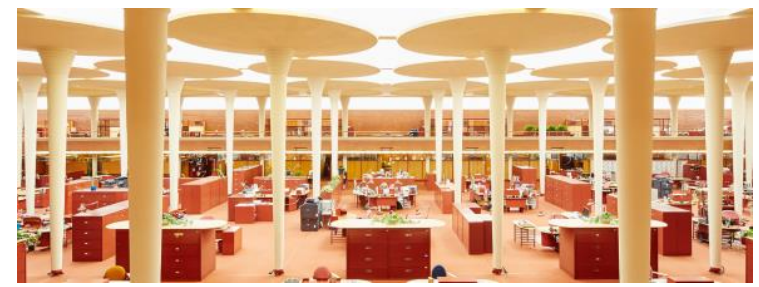

Figure 2: S.C. Johnson \& Son Admin building was opened in 1939 Racine, WI, USA [11]

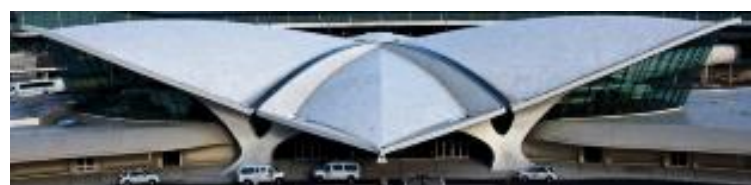

Figure 3: TWA Terminal Building was designed by Calatrava and Eero Saarinen's and was opened in 1962, New York, USA [10]

\subsection{Biomimetic Approaches}

After surveying, and explaining the different biomimetic technologies that are used in the design process, the bio-mimicry approaches in architecture are divided into the following: [5] [6]

\subsubsection{Design with A Biological Reference}

The first approach occurs when the design problems are defined. Then, the designer tries to find out how organisms and ecosystems can solve similar problems, see Figure 4. It is considered the most common approach of bio-mimicry science. However, it requires a multispecialists and collaborative team of biologists, ecologists, and engineers. [5]

\subsubsection{Biology Influences Design}

The second approach depends on biological or ecological knowledge, such as some or many characteristics, behaviors, or functions in an organism or ecosystem, then translating this knowledge into the design process, see Figure 5. In this approach, it is important firstly to test this knowledge for the design context and human's suitability before the application process. [5] [12]
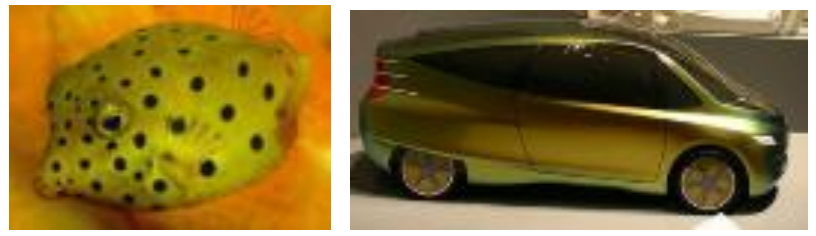

Figure 4: Strengths characteristics of the Box' fish (left) was inspired for the prototype of Daimler Chrysler's car to minimize stress (right) [5]
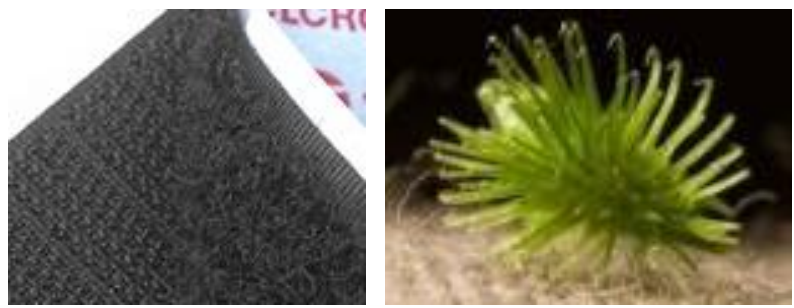

Figure 5: Velcro Hook \& Loop fasteners (left) [14] mimics the tangle characteristics of the Burdock seeds (right) [13]

\subsection{Biomimetic Levels}

Zari. $\mathrm{M}$ was examining the biomimetic principles and applications from different fields such as medical, engineering, arts, and architecture. Then she proposed a framework for understanding the levels and dimensions of biomimicry science in architecture as follows (see Figure 6): [5] [6]

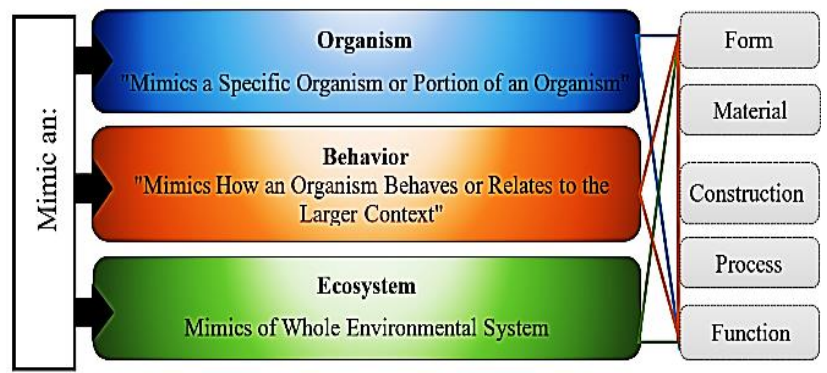

Figure 6: Levels and Dimensions of the Biomimetic Architecture [5]

\subsubsection{Organism}

The first level is the organism that mimics a specific organism or a portion of an organism. A remarkable example of this level is the Hydrological Center building in the University of Namibia that has been mimicked from the Namibian desert beetle, as shown in Figure 7.

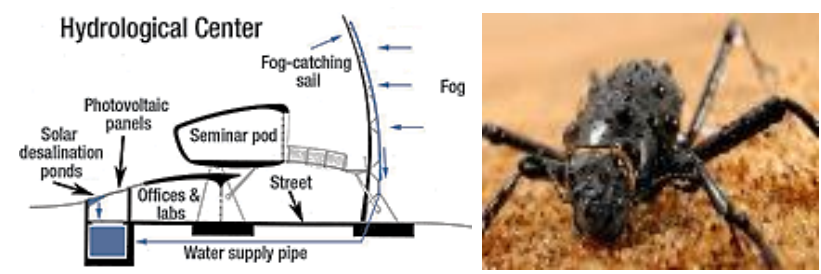

Figure 7: Water drops' collector envelope of the Hydrological Center building to clear fog (left) [4] mimicked from the dewdrop collector form of the Namibian desert beetle (right) [15]

\subsubsection{Behavior}

The behavior level means the act of mimicking the behaviors of an organism and the relations between its larger contexts. The East Gate Building, Harare, Zimbabwe is the most cited example of this level that mimicked the cooling system from the termite nest, as shown in Figures 8. 


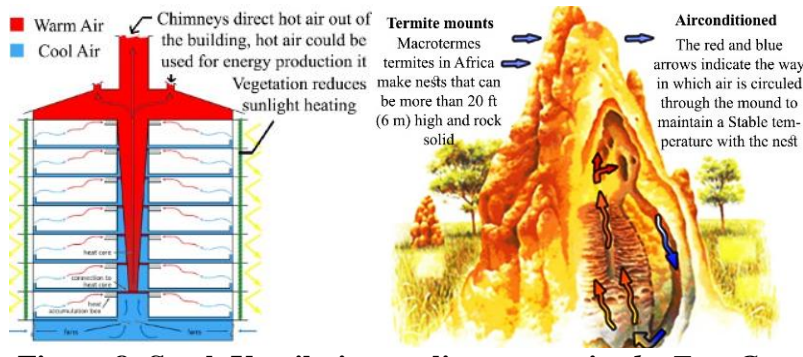

Figure 8: Stack Ventilation cooling system in the East Gate Building [16] (left) mimicked from Termite Nest cool system [17] (right)

\subsubsection{Ecosystem}

The last level is the ecosystem. It is an integral level that mimics a whole environmental system. Zira Island, Baku, Azerbaijan is an example of that level. This project was inspired by the seven peaks of Azerbaijan, which form the skyline view, as shown in Figure 9. It is also considered a model of Ecosystem Island that depends on natural energy resources, which are the sun, the water, and the wind, see Figure 10.

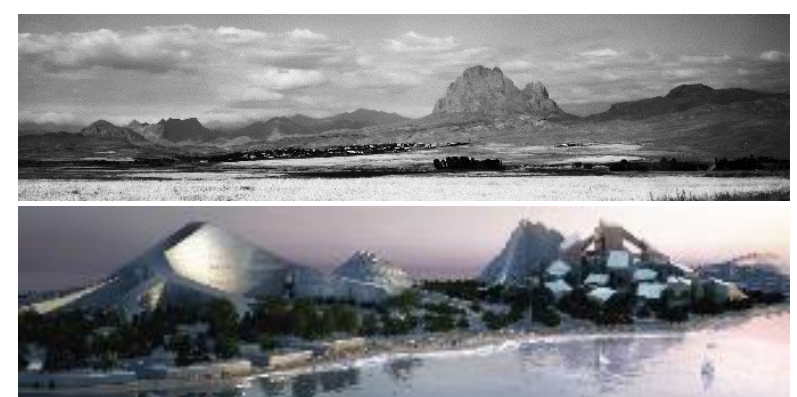

Figure 9: Seven peaks of Azerbaijan that form Skyline view of Baku, Azerbaijan (up) is inspired for the Zira Zero Island project, Baku, Azerbaijan (down) [18]

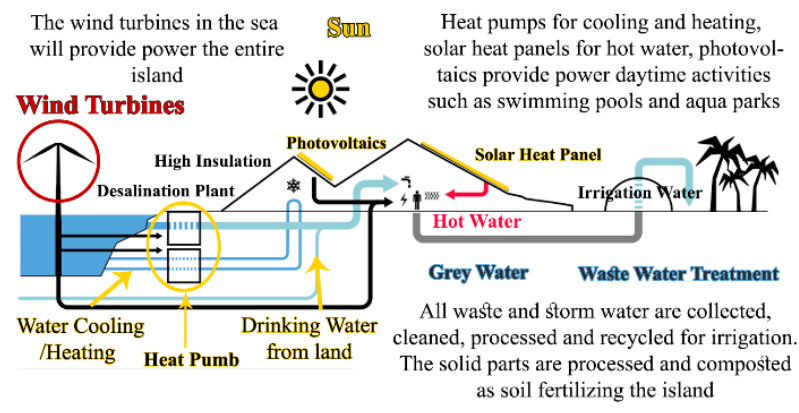

Figure 10: Zero Island project completely depends on the sustainable energy resources derived from the surround environmental resources such as water, sun, and wind [4]

[18]

\section{CHAMELEON}

Chameleon, a species of vertebrates, is an ectothermic organism that depends on gaining the most heat of its body directly from the surrounding environment. [19]

There are countless species of chameleons. They inhabit the open area of the desert and grassland. Some species live in hot arid climatic zones. [19] Their lifespan ranges between 2 to 10 years according to their species. Chameleon is oviparous and feeds on insects, other lizards, and young birds. Sometimes it feeds on leaves to compensate water level. Some species of chameleon can regulate vitamin D3 in their body from the sun. [20]

\subsection{Color Change Skin}

Each organism can survive and adapt to the environment with its characteristics and specific body components. The chameleon is one of the most incredible and amazing organisms that can change its skin's color. This change happens for many reasons such as the thermoregulation property of the body, the social communication for mating, or the camouflage capability to avoid predators. Chameleon has the ability to avoid about $45 \%$ of sun rays through skin reflection. [21] [22] [23]

\subsection{How Color Change Happens}

The property of the color change occurs by the structure, shape size, and the presence of a physical component called chromatophores in the skin composition. [21] [22] [24] Chromatophores are pigment-containing and light-reflecting cells. They are generated in the neural crest during the embryonic development. They are responsible for producing skin and eye color. [25] Although there are many types of chromatophores, only the iridophores and melanophores are responsible for the effect of color change in the chameleon, as shown in Figure 11. [21]
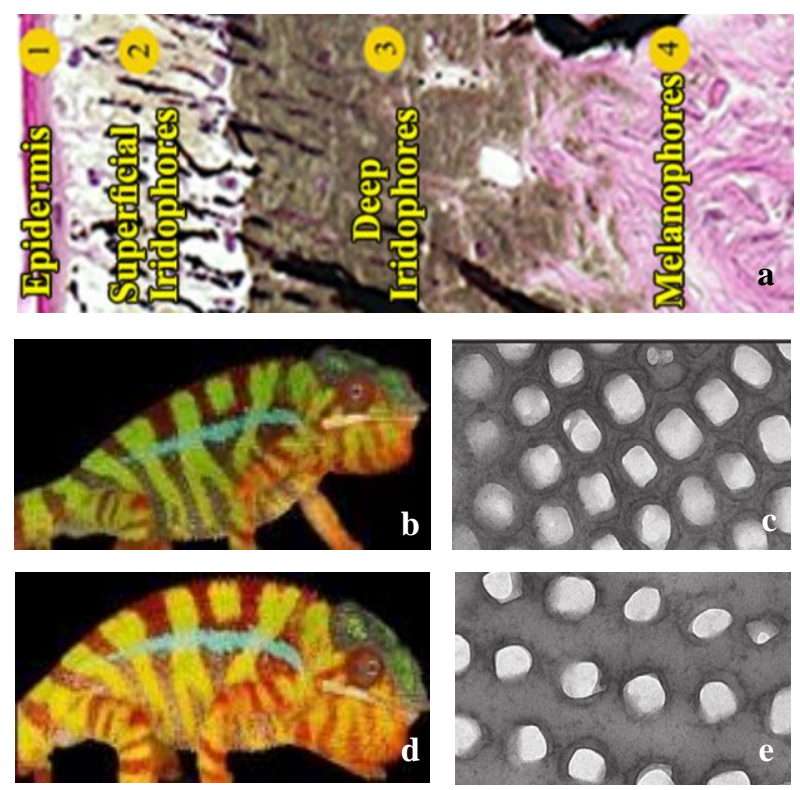

Figure 11: Chameleon skin and color change; (a) chameleon skin layers, (b) while it in relaxation mode (c) iridophores are attached to reflection sun rays, and (d) while it in exciting mode (e) iridophores separated to let sun rays inter [21] 


\section{METHODOLOGY}

The proposed methodology in this paper is divided into two main axes, as shown in Figure12. The first is reviewing the international case studies of buildings that mimic chameleons and analyzing each case according to:

- Their Design Concept;

- The Applied Technologies and Materials

In the second part, those case studies have been analyzed and classified according to biomimetic architecture levels.

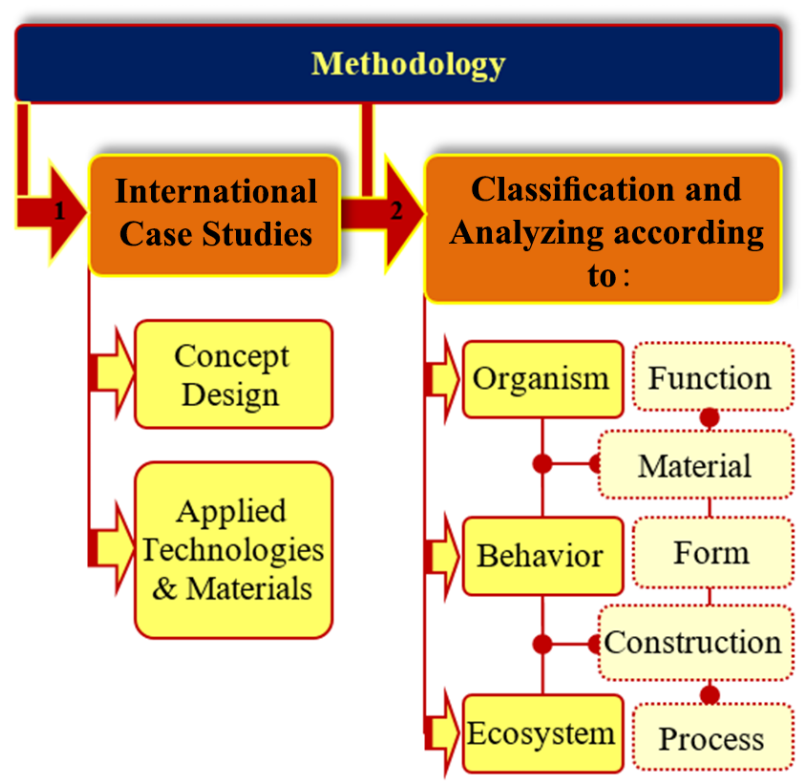

Figure 12: Schematic diagram for research methodology proposed by the researcher

\section{INTERNATIONAL CASES STUDIES}

Only very few implemented projects have been inspired by the Chameleon. Although most of the following cases studies are just bioinspired proposals, each case suggested a unique design concept integrated with an advanced responsive technology.

\section{1. Šiauliai Arena, Lithuania}

Šiauliai Arena, a multifunctional building, was constructed for the European Men's Basketball Championship of 2011 in ŠIAULIAI Town, Lithuania, see Figure 13. It was built in 2006 with an area of 19600 $\mathrm{m} 2$. The building consists of five floors with a diameter of $100 \mathrm{~m}$ and a height of $19 \mathrm{~m}$. [26] [27]

\subsubsection{Design Concept}

The word ŠIAULIAI means the "Sun". Therefore, the architects selected the cylindrical form to symbol the town with the impression of the solar glow to be visually unforgettable as a chameleon. [28]

\subsubsection{Applied Technology and Materials}

To investigate this chameleonic vision, the architects applied the holographic glass in the whole cylindrical façades. Holographic glass makes the building shown in various colors depending on the point of view, sun rays angle, and illumination. The holographic window units consist of double glass panes with gluing a special sun rays scattering film. In cloudy days, it appears dark or solid color and in sunny days, the glazing façade appears colored, as shown in Figure 13. [27] [29]

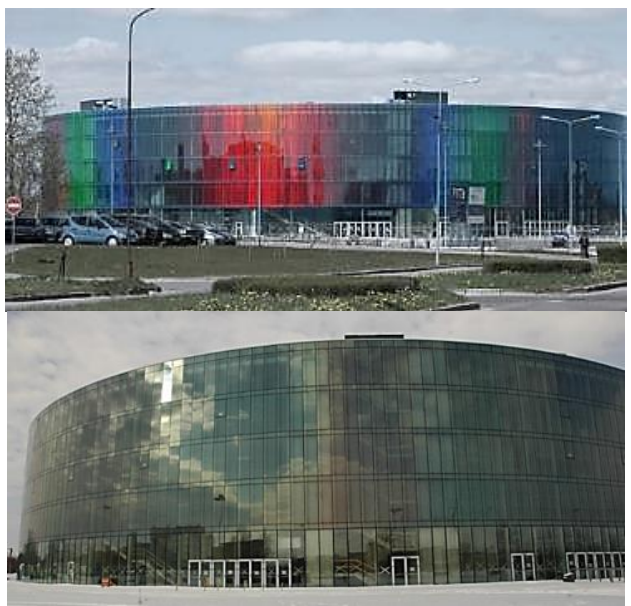

Figure 13: The Šiauliai Arena appearance in sunny days (up) [27] and in cloudy days (down) [26]

\subsection{Office Building for D3, Dubai}

The chameleon biomimetic office building is a proposed project that won the first prize in a mixed-use office building competition in 2015, in Dubai, see Figure 14. [30] [31]

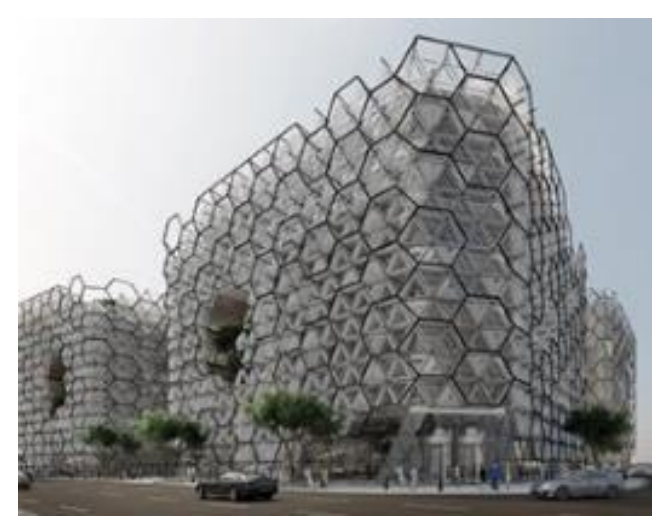

Figure 14: Proposed design of chameleon office building, District 3, Dubai

\subsubsection{Design Concept}

After analysing the project location, WWF architects concerned the principles of biomimicry in the proposed design. They applied a hexagonal shape in the building facades inspired by the chameleon skin pattern, as shown in Figure 15. [30] 

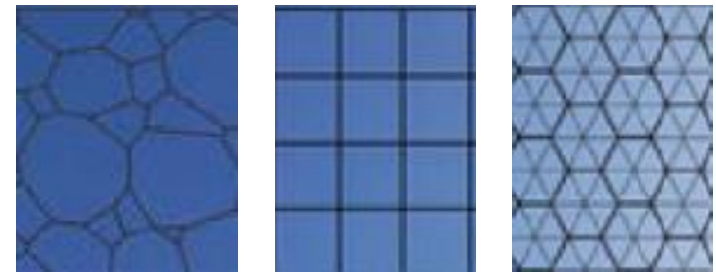

Figure 15: chameleon skin pattern (left) was inspired based on a grid pattern (middle) to hexagonal pattern (right) [32]

\subsubsection{Applied Technology and Materials}

The project façades were designed to adapt mechanically with the sun path to control internal temperature, as shown in Figure 16. [30] The sun path is inconstant angel between sun rays and the horizontal plane [31], as shown in Figure 17. When the angel is about $85{ }^{\circ} \mathrm{C}$ or more the façades open to gain sun rays and when the angel is about $15^{\circ} \mathrm{C}$ or less it closes to block sun rays.

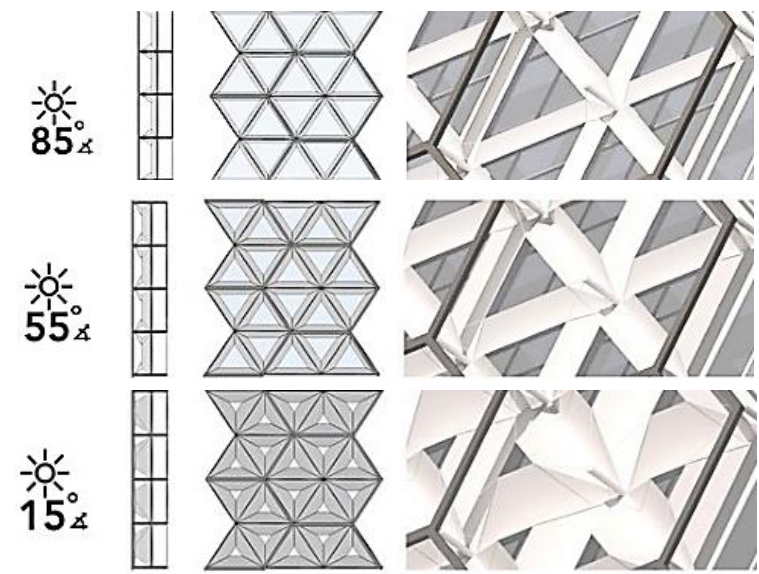

Figure 16: Adaptivity of the facades according to sun trajector [32]

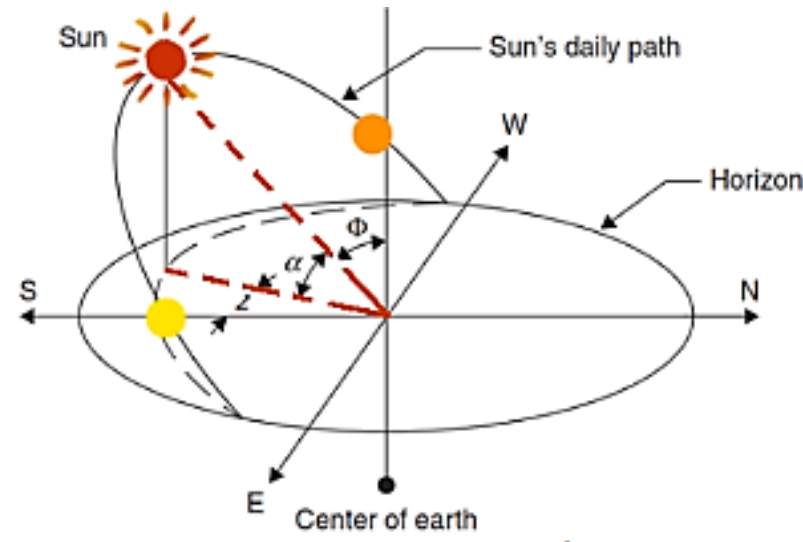

Figure 17: Sun path Angel ( $\lessdot)$ [33]

In addition, photovoltaic nano cells have been applied at the outer layer of the left façade in order to collect the solar energy during the day and to be reused as illuminating energy source for thousands of multicolored LED at night, see Figure 18. [31]
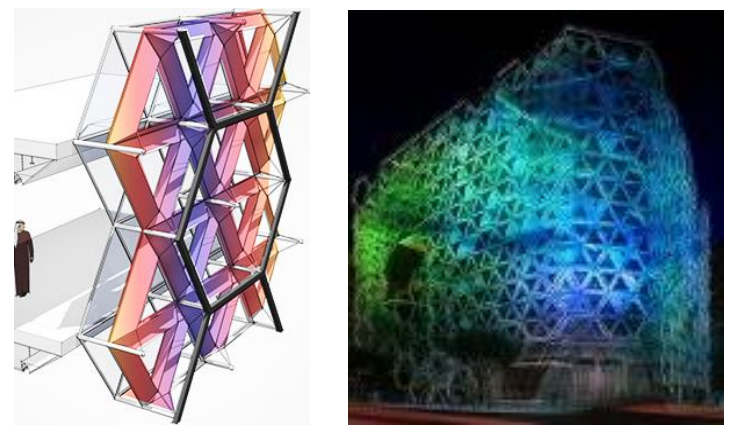

Figure 18: Photovoltaic nano cells located in the outer layer of the façade (left) that illuminate at night (right) [32]

\subsection{PROPOSED RESEARCH, MANUFACTURING, AND THERAPY FACILITY FOR ADVANCED PROSTHETICS}

A research, manufacturing, and therapy facility building for advanced prosthetics building is a proposed project connected to the Spaulding Rehabilitation Medicine building in Boston, Massachusetts, see Figure 19. [4]
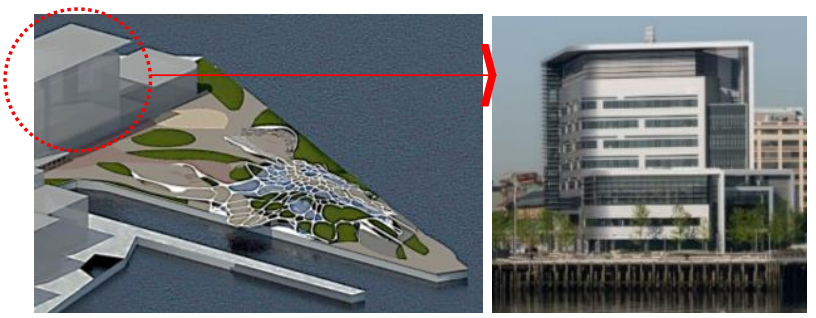

Figure 19: The proposed design building [4] (left) beside the Spaulding Rehabilitation Medicine (right) [34]

\subsubsection{DESIGN CONCEPT}

The proposed project is a biomimetic design inspired by the spongy bone in the human Skelton in addition to the adaptive skin of the Namaqua chameleon.

The first biomimetic part is human skelton. The human skelton is a structural bone consists of two bones types; compact and spongy. The compact bone exposes the main mechanical stress and forces that we face every day while covers and protects the spongy bone, see Figure 20 . The spongy bone is a light and very porous pattern that allows some flexibility for body movement without breakage. Therefore, Maglic, $\mathrm{M}$ proposed a concrete arterial structure inspired by spongy bone in human Skelton. [4] [35]

The second biomimetic part refers to the Namaqua Chameleon that lives in the Namib Desert, north of South Africa, as shown in Figure 20. In addition to high solar radiation, the average temperature in this area from November to March is about $32{ }^{\circ} \mathrm{C}$ at day and goes down to $7{ }^{\circ} \mathrm{C}$ at night. Namaqua chameleon can control heat gain or loss by changing skin color from dark to light 
respectively, to survive in intensive climatic conditions. As a result, Maglic proposed an adaptive skin that could regulate the internal temperature in the proposed project. [4]
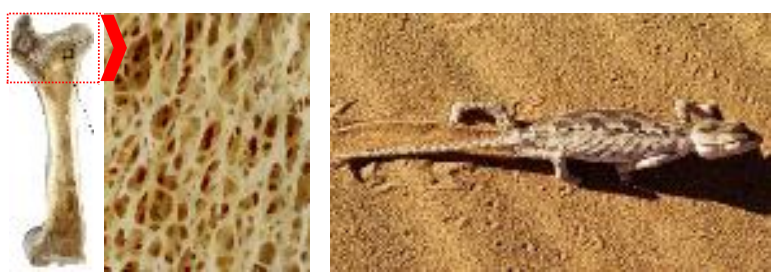

Figure 20: Spongy bone in human Skelton [35] (left) Namaqua Chameleon (right) [4]

\subsubsection{Applied Technology and Materials - Adaptive Fritted System}

To ensure the proposed adaptive temperature regulation skin, Maglic applied the fritted glass system. [4] Adaptive Fritting ${ }^{\mathrm{TM}}$ system is a multi-layers of fixed circled acrylic patterns stacked in orthogonal axes. The motion of those axes is controlled by an electromagnetic motor to spread the circles as fan wings and to cover the interspaces between them. The panel modulates between opaque and transparent states through the fritted converging or diverging respectively, as shown in Figure 21. [36] [37]
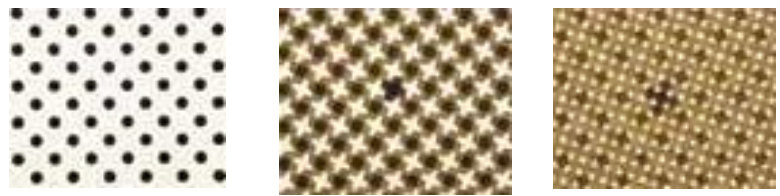

Figure 21: Adaptive fritting system transforms from transparent (left), semitransparent (middle), and opaque status (right) [37]

\section{- Solar Collectors}

As a result, the researcher proposed an adaptive fritted system in which the acrylic patterns are replaced by thin solar collector films. Controlling the heat gain or loss can be achieved by changing the transparency or opaque status of the panel respectively while generating solar energy, as shown in Figure 22. Some panels are fixed and the others are operable to achieve a passive natural ventilation, see Figure 23. An additional technology, which is a unique water catchment system, has been installed. A collecting rainwater network has been placed along with the structure system. This water could be recycled and reused again, see Figure 23. [4]
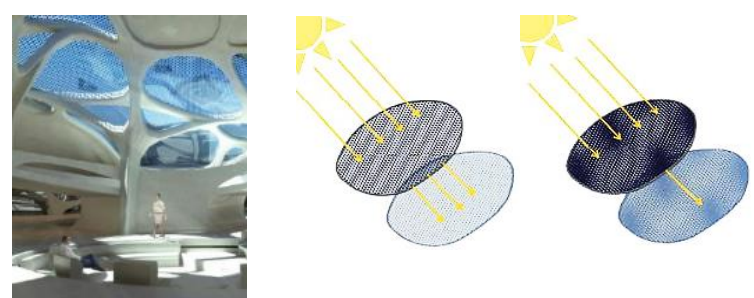

Figure 22: Natural daylight in internal spaces (left) while transforms from transparent to opaque status (right) [4]

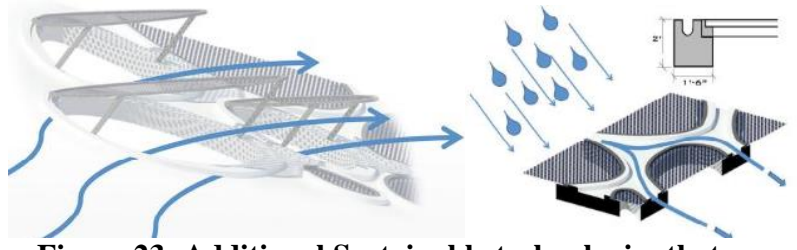

Figure 23: Additional Sustainable technologies that are included into the design process; operable fritted panels for natural ventilation (left) and water catchment system

(right) [4]

\subsection{S.C.A.L.E.S. PROJECT}

S.C.A.L.E.S is an abbreviation for Smart, Continuous, Active, Layered, Environmental, and System. S.C.A.L.E.S is a small artists studio prototype proposal located in the Great Basin Desert, Utah, the United State. The project is designed by Mazzoleni, I. with her teamwork, see Figure 24. [19]

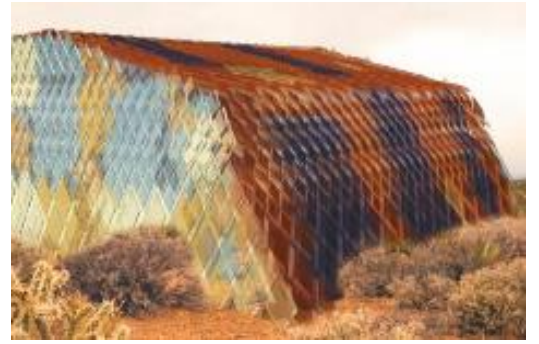

Figure 24: S.C.A.L.E.S proposed prototype project [19]

\subsubsection{Design Concept}

The main concept of the prototype project is mimicking the efficient thermoregulation property in the common side-blotched lizard. Some species of the common side-blotched lizards inhabit arid regions such as Mexico, Washington, Texas, and the pacific coast. [19]

The common side-blotched lizards have the ability to regulate their body temperature through the integration of two techniques. The first is the colored pattern in the skin composition; the dark color on the lizard's back is responsible for absorbing heat. On the other hand, the light color in the abdomen is responsible for reflecting the ground heat, see Figure 25. The second technique is about their behavioral movements such as standing parallel to sun rays to avoid heat, vertical to sun rays to gain heat, or curling their toes to avoid heat gain, as shown in Figures 25\&26. In the extremely hot hours, they hide in the shade, as shown in Figure 26. [19]
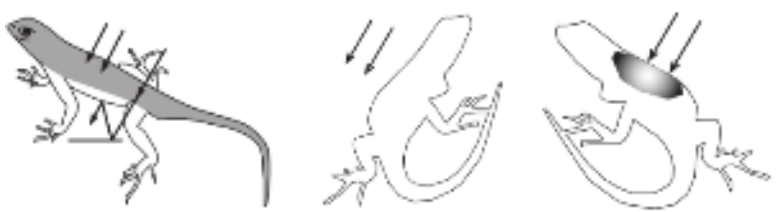

Figure 25: Thermoregulation Techniques in the SideBlotched Lizards dark and light colors (left), parallel (middle), or vertical posture to sun rays (right) [19] 

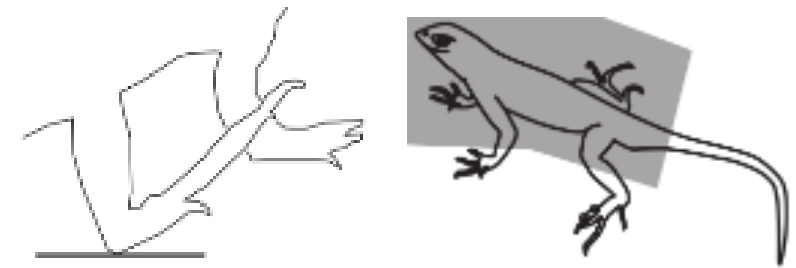

Figure 26: Bending toes to avoid heat gain from the ground by conductive (left) and hiding in shades to avoid extreme heat (right) [19]

The proposed location of the project has an average temperature of about $-18{ }^{\circ} \mathrm{C}$ in winter and about $50{ }^{\circ} \mathrm{C}_{\text {in }}$ summer months. Therefore, the main concept is proposing an adaptive envelope inspired by sideblotched lizard to regulate the internal spaces temperature and achieve the thermal comfort for the users in the variations in desert climates [19]

\subsubsection{Applied Technology and Materials}

The proposed envelope is a sun-tracking envelope consists of three different compositions fixed on a braced steel grid, as shown in Figures $27 \&$ 28. [19]

The south façade consists of photovoltaics. Photovoltaic panels are used to collect sunlight and convert it into energy. The second composition is installing operable windows to allow passive natural ventilation, see Figure 29. [19]

The third composition is a bio-based phase change material. [19] Phase Change Material is a type of functional materials that can store thermal energy as a latent heat when a substance changes from phase to another either by melting or by freezing. [38] PCM is classified into organic, inorganic, and eutectic materials. [39]

PCM is used to insulate and cool the internal spaces during the day, while collects and stores heat then releases it at night. The other facades follow the same arrangement strategy but may differ in their composition according to the sun orientation. [19]

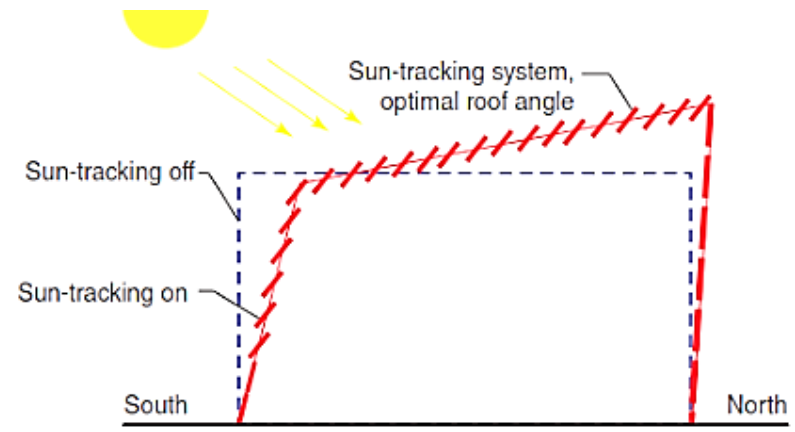

Figure 27: Sun tracking envelope while on and off to be positioned to sun [19]

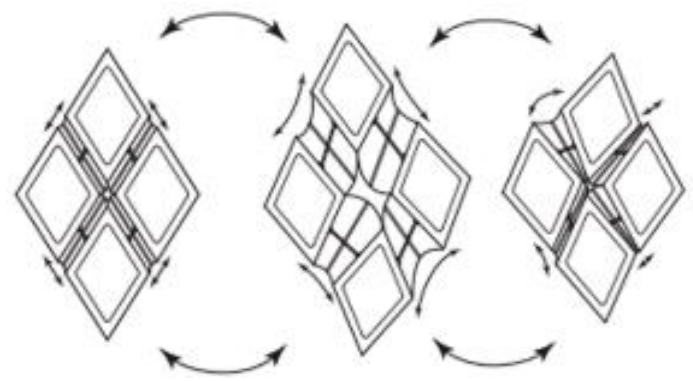

Figure 28: Envelope expansion to track the sun [19]
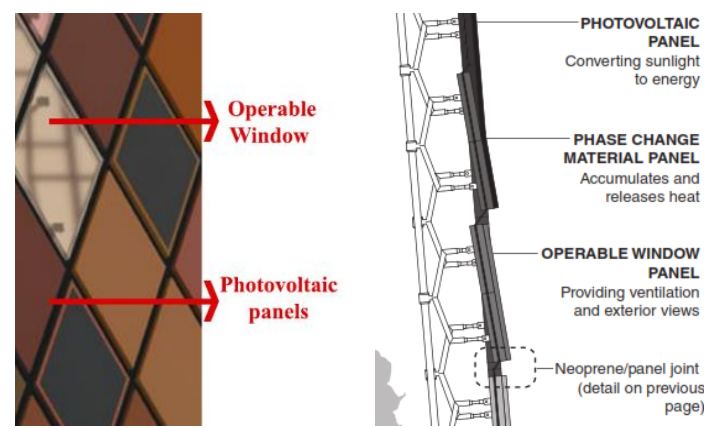

Figure 29: Photovoltaic and operable windows (left) specification of the south façade composition layers (right)

[19]

\section{CASE STUDIES ANALYSIS}

Before analysing the international case studies, it was important to classify each case according to the three biomimetic levels, which are organism, behavior, and ecosystem levels previously mentioned in the methodology. Each level was classified according to five dimensions (form, material, construction, process, and function). All cases with their biomimetic levels and dimensions have been represented in Table 1 .

Based on the table and according to the proposed classification of the applied techniques inspired by the chameleon in the three-biomimetic levels, we noticed that in the first case study "Šiauliai Arena" the designer was inspired by the unusual colorful appearance of the chameleon (organism level) more than the behavior. Furthermore, just few chameleon's capabilities related to adaptive purposes have been mimicked.

Second project (the Mixed-Use Office Building in Dubai) could be considered as a reversible concept if compared to the previous one. Although the hexagonal shape of the façade glazing units seems to be partly inspired by the chameleon's skin pattern, it is obvious that the design concept in that case focused mainly on the behavior level by using the adaptive façade to control the indoors temperature and the daylight transmission. In addition, the designer reached the ecosystem level by applying the photovoltaics unit on the left façade, which makes this project more efficient, and have a greater impact on the built environment. 
The third case study (Manufacturing, and Therapy Facility for Advanced Prosthetics in USA) is unique. We can feel a harmony between the three-biomimetic levels integrated in the design concept to get an eco-friendly building with high-energy performance. In that case, the designer tried to combine the capabilities of more than one organism, the human sponge bone, with the adaptive skin of the Namaqua chameleon by using the adaptive solar fritted panels. Besides, some sustainable solutions with a high technology have been applied to support the ecosystem level as using the natural ventilation in the building envelope in addition to the installation of the rainwater collectors along with the building structure.

The last project (S.C.A.L.E.S. PROJECT, Great Basin Desert in Utah, USA) is surrounded by very harsh environmental conditions with an extreme variation between temperatures in summer and winter days. In these conditions, the behavior level was crucial to mimic the thermoregulatory property of the lizard accompanied with additional high technics such as sun tracking system to regulate the internal temperature and the colored photovoltaics panels to produce energy and at the same time support the biomimicry concept.

As an overview of the previous projects, we can assume that mimicking an organism is a very complicated process. Each level of biomimicry can have versatile modes of applications, based on many factors, which can lead the architect to choose the more convenient level to each case. The location, the weather, the project type, the natural resources, and the available technologies could be some of the factors that should be taken under consideration during the design concept phase. Furthermore, other biological organisms could have several inspiring properties, which can help in the design process, especially in extreme climates.

\section{CONCLUSION}

Applying the biomimicry principles in architecture can have a great impact on the design process. These principles can help to innovate new sustainable design solutions in order to reduce the energy consumption in the built environment.

The chameleon is a unique organism, which can survive efficiently in arid climate. This organism can be considered as a great model of Biomimetic Architecture to produce different design concepts. The unique characteristics of the chameleon, its behavior or the combination of both can be integrated with high technological capabilities to achieve our target.

Based on the analyzed studies, we could conclude that using the physical characteristics of the chameleon alone could not be a smart choice. Bedsides, mimicking the chameleon behavior along with the physical appearance could have a greater impact on the built environment. Furthermore, having an integrated methodology based on more than one capability or even more than one organism could achieve better performance.

Although very few projects have been conducted until now using the chameleon model in addition to some bioinspired proposals, this model showed recently a great interest from many researchers trying to explore more creative and integrated adaptive solutions to be applied in architectural buildings.

\section{Credit Authorship Contribution Statement:}

Yasmin M. Eid: Generating the idea, Collecting data, Methodology, and Original draft preparation, Mostafa A. El Ahwal: Reviewing \& Supervision, Magda E. Ebied: Reviewing \& Supervision, Rania H. Aly: Validation, Editing, Reviewing \& Supervision.

\section{Declaration of Competing Interest:}

The authors declare that they have no known competing financial interests or personal relationships that could have appeared to influence the work reported in this paper.

\section{References}

[1] N. Ramzy, "Biophilic qualities of historical architecture: In quest of the timeless terminologies of 'life' in architectural expression," Sustainable Cities and Society, pp. 42-56, 2015.

[2] J. Benyus, "Biomimicry: Innovation Inspired by Nature," Harper Perennial, 2002.

[3] W. Schreiner, "Biomimicry: A History," The Department of History at Ohio State University, 19, April 2018 . [Online]. Available: https://ehistory.osu.edu/exhibitions/biomimicry-ahistory. [Accessed 15 November 2019].

[4] M. Maglic, Biomimicry: Using Nature as a Model for Design, University of Massachusetts Amherst, 2012.

[5] M. Zari, "Ecosystem Services Analysis for The Design of Regenerative Urban Built Environments," Victoria University of Willington, New Zealand, 2012.

[6] M. S. Shahda , A. A. E. Elmokadem and M. M. Abd Elhafeez, "Biomimicry Levels as an Approach to The Architectural Sustainability," PORT SAID ENGINEERING RESEARCH JOURNAL, p. 117:125, 2014.

[7] L. Pett, The bio building : bio inspired design at Algard Mill and Saw, Gothenburg: Chalmers University of Technology, 2016, pp. 1-75.

[8] B. Bajçinovci, "Biomimicry and Biophilic Design: Multiple Architectural Precepts," Journal of Science, Humanities, and Arts, pp. 1-10, 2019. 
[9] S. Khoshtinat, Agorithms in Nature and Architecture, Italy, 2016.

[10] M. Nessim, BIOMIMETIC ARCHITECTURE AS A NEW APPROACH FOR ENERGY EFFICIENT Buildings, Cairo: Cairo University, 2016, pp. 1-154.

[11]"Designed to Inspire Sc-johnsons Frank Lloyd Wright Designed Administration Building," SCJohnson, [Online]. Available: https://www.scjohnson.com/en/a-familycompany/architecture-and-tours/frank-lloydwright/designed-to-inspire-sc-johnsons-frank-lloydwright-designed-administration-building. [Accessed 15 December 2019].

[12] M. Zari, "Biomimetic Approaches to Architectural Design for Increased Sustainability," Victoria University of Willington, School of Architecture, New Zealand, 2007.

[13] K. Varma, "Biomimicry what is it and what does it mean," Land 8 Media, [Online]. Available: https://land8.com/biomimicry-what-is-it-and-whatdoes-it-mean-for-landscapearchitects/velcro_seed1/. [Accessed 25 November 2019].

[14]"VELCRO®," Hook \& Loop Fasteners, [Online]. Available:

https://www.hookandloopfasteners.co.uk/fasteners/v elcro-brand-50mm-black-self-adhesive-permetre.html. [Accessed 25 November 2019].

[15] E. Fredrick, "Could this desert beetle help humans harvest water from thin air?," American Association for the Advancement of Science., 27 November 2019. [Online]. Available: https://www.sciencemag.org/news/2019/11/coulddesert-beetle-help-humans-harvest-water-thin-air. [Accessed 29 November 2019].

[16] "Eastgate Centre,Harare," Wikiwand, May 2014. [Online]. Available: wikiwand.com/en/Eastgate_Centre,_Harare. [Accessed 05 January 2020].

[17] J. Hwang, Y. Jeong, J. Park, K. Lee, J. Hong and J. Choi, "Biomimetics: forecasting the future of science, engineering, and medicine," International Journal of Nanomedicine, pp. 5701-5713, 2015.

[18] "ZIRA ISLAND: Central Asia's First Carbon Neutral Master Plan in Baku, Azerbaijan," AVROSITI Holding, 2009. [Online]. Available: https://www.ziraisland.com/. [Accessed 15 Novmber 2019].

[19]I. Mazzoleni, Architecture Follows NatureBiomimetic Principles For Innovative Design, CRC Press, Taylor \& Francis, 2013, pp. 1-245.

[20] "Chameleon," Wikipedia.org, [Online]. Available: https://en.wikipedia.org/wiki/Chameleon. [Accessed 12 August 2019].

[21]J. Teyssier, S. Saenko, D. Marel and M. Milinkovitch, "Photonic Crystals Cause Active Colour Change in Chameleon," Nature Communications, pp. 1-7, 2015.
[22] H.-H. Chou, A. Nguyen, A. Chortos, J. W.F. To, C. Lu, J. Mei, T. Kurosawa, W.-G. Bae, J. B.-H. Tok and Z. Bao, "A chameleon-inspired stretchable electronic skin with interactive colour changing controlled by tactile sensing," Nature Communication, pp. 1-10, 2015.

[23] Q. Wang, G. Gossweiler, S. Craig and X. Zhao, "Cephalopod-inspired Design of Electro-MechanoChemically Responsive Elastomers for On-Demand fluorescent Patterning," Nature Commuincation, pp. $1-9,2014$.

[24]D. Stuart-fox, "How Do Chameleon and Other Creatures Change Color," 2013. [Online]. Available: https://phys.org/news/2013-05-chameleonscreatures-coloures.html. [Accessed 18 November 2018].

[25]J. Kelly and W. Davies, "The Biological Mechanisms and Behavioral Functions of OpsinBased Light Detection by the Skin," Frontiers in Ecology and Evolution, vol. 4, pp. 1-13, 2016.

[26]"SIAULIU ARENA," Mi Modern Architecture , 2011. [Online]. Available: Https://www.Mimoa.Eu/Projects/Lithuania/Siauliai/ Siauliu\%20arena/. [Accessed 15 January 2020].

[27]"Siauliai Arena / E. Miliuno studija + Dvieju Grupe," Arch Daily, 10 October 2009. [Online]. Available:

https://www.archdaily.com/38742/siauliai-arena-emiliuno-studija-dvieju-grupe.[Accessed 15 January 2020].

[28] "Siauliai Arena," Jidipi Architectures, 31 July 2006. [Online]. Available: https://architectures.jidipi.com/a119180/siauliaiarena/. [Accessed 15 January 2020].

[29]"Hologram in Window," Glimm Display, [Online]. Available: https://www.glimmdisplay.com/windowdisplay-solutions/hologram-in-window/. [Accessed 05 February 2020].

[30]"WWF Architects Chameleon Mixed Use Office Building," Design Boom, 2015. [Online]. Available: https://www.designboom.com/architecture/wwfarchitects-chameleon-mixed-use-office-building-1230-2015/. [Accessed 17 February 2020].

[31]"Arch 655: Project 1," Parametric BIM, 24 October 2016. [Online]. Available: http://parametricbim.blogspot.com/2016/10/arch655project-1_24.html. [Accessed 18 February 2020].

[32] "The Chameleon," WANDERS WERNER FALASI consulting architects, [Online]. Available: http://www.wwf-architects.com/index\#/thechameleon/. [Accessed 20 February 2020].

[33]S. Kalogirou, "Environmental Characteristics Process and Systems," in Solar Energy Engineering, Second ed., Elsevier, 2014, pp. 51-123.

[34] "Spaulding Hospital / Perkins+Will," Arch Daily, 2013. [Online]. Available: 
https://www.archdaily.com/443408/spaulding-

hospita-perkins-will. [Accessed 19 February 2020].

[35] P. Bishop, S. A. Hocknull, C. Clemente, J.

Hutchinson, A. Farke, B. Beck, R. Barrett and D. G.

Lloyd, "Cancellous bone and theropod dinosaur locomotion. Part I-an examination of cancellous bone architecture in the hindlimb bones of theropods," PALEONTOLOGY AND EVOLUTIONARY SCIENCE, pp. 1-6, 2018.

[36] I. Hoberman Associates, "Statement of Qualifications," 2011. [Online]. Available: http://www.hoberman.com/about.html. [Accessed 28 February 2020].

[37]Z. Drozdowski and s. Gupta, "Adaptive Fritting as Case Exploration for Adaptivity in Architecture," in
Building a Better Tomorrow , Chicago, Illinois, 2009.

[38] K. Muruganantham, P. Phelan, P. Horwath, D. Ludlam and T. McDonald, "EXPERIMENTAL INVESTIGATION OF A BIO-BASED PHASECHANGE MATERIAL TO IMPROVE BUILDING ENERGY PERFORMANCE," in 4th International Conference on Energy Sustainability, Arizona, USA, 2010.

[39] A. Hassan, M. Laghari and Y. Rashid, "MicroEncapsulated Phase Change Materials: A Review of Encapsulation, Safety and Thermal Characteristics," Sustainability, p. 32, 2016.

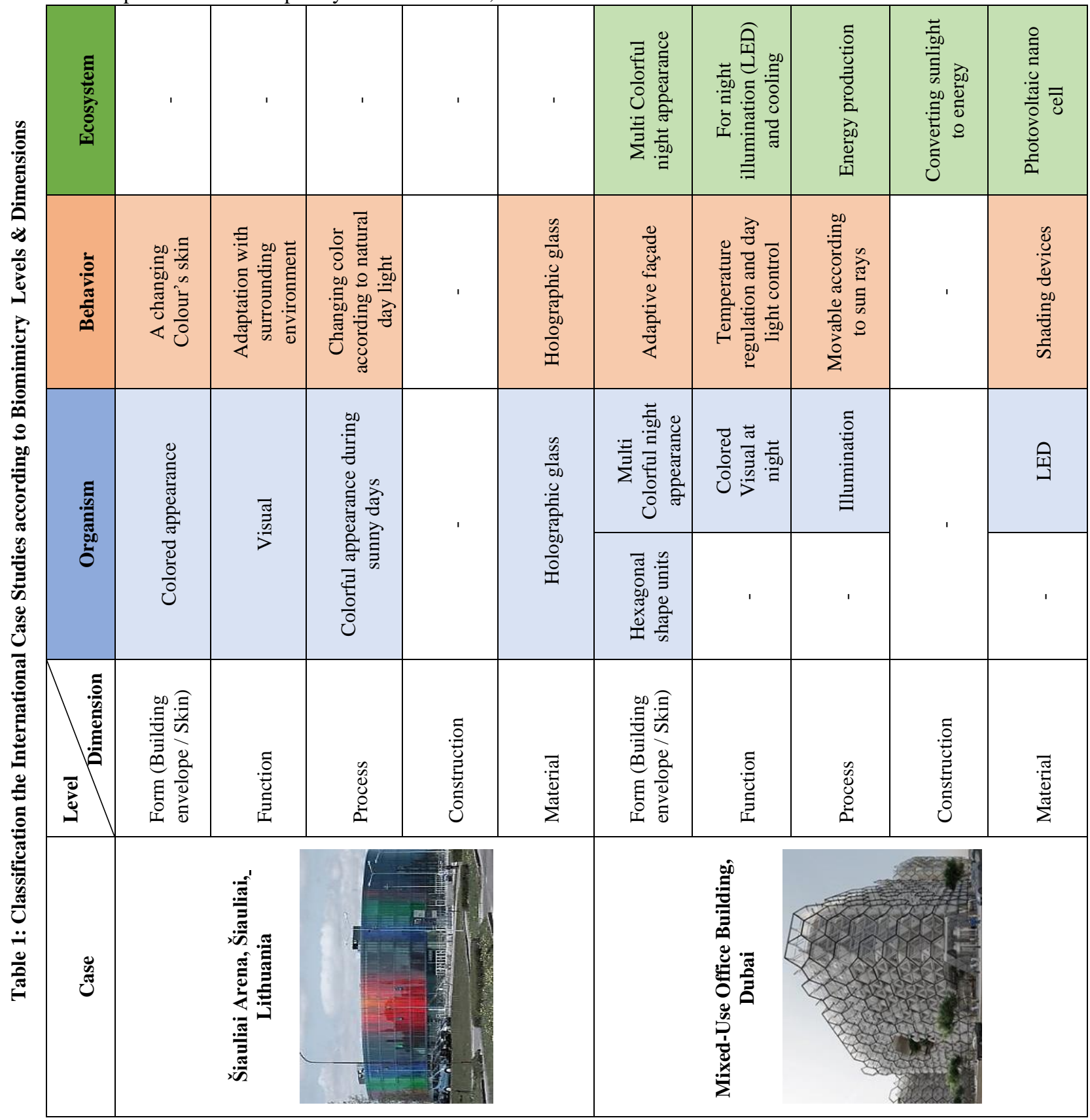




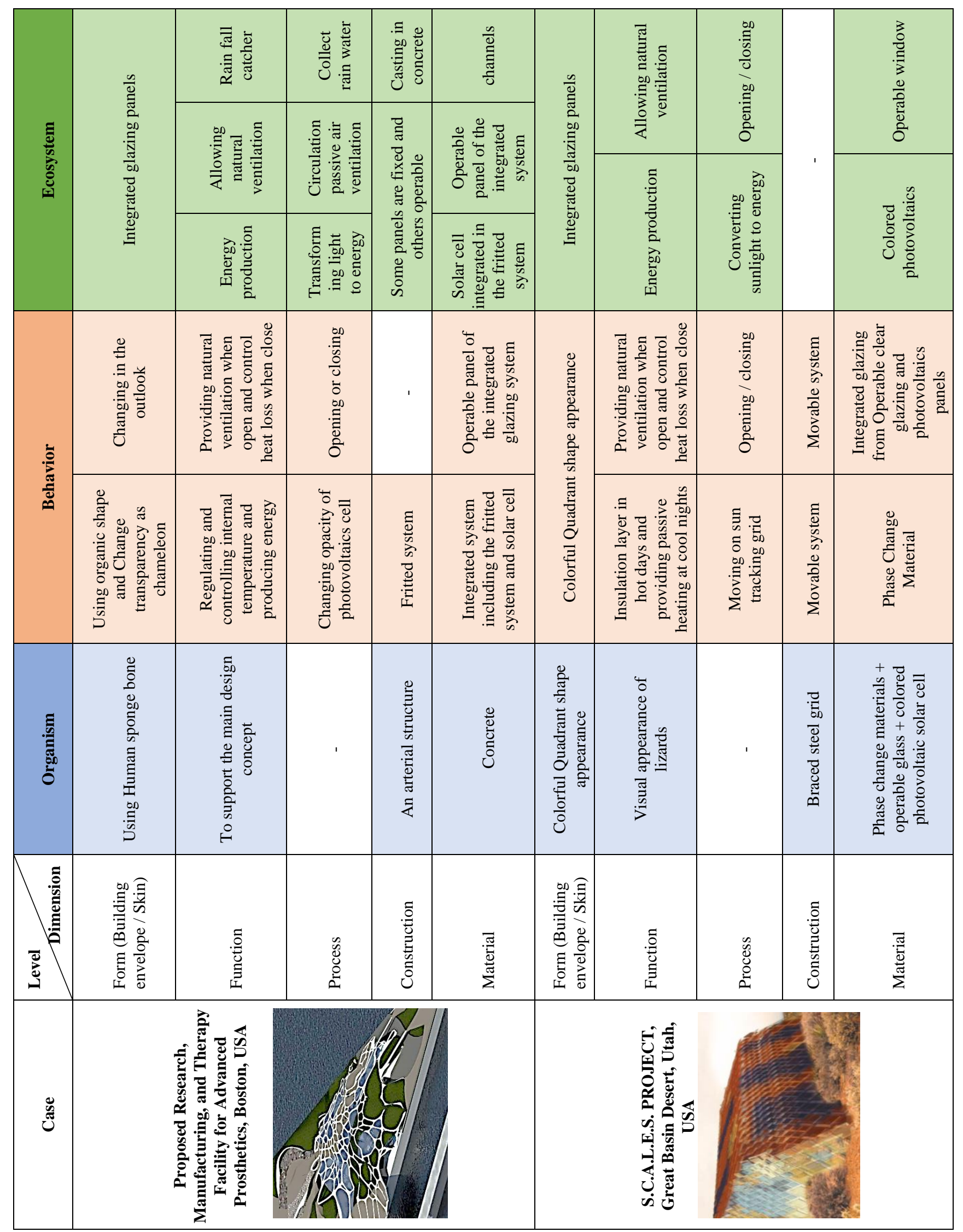

